\title{
CAFFEINEAS A PROMISING ANTIFBROTIC AGENT AGAINST CCL4-INDUCED LIVER FIBROSIS
}

\author{
MOSTAFA KAMAL MOHAMED*, MARWA MAHMOUD KHALAF, AMIRA MORAD ABO-YOUSSEF, \\ ALI AHMED ABO-SAIF
}

Department of Pharmacology and Toxicology, Faculty of Pharmacy, Nahda University, Beni-Suef, Egypt

Email: m_k_88882000@yahoo.com

Received: 17 Jan 2017 Revised and Accepted: 20 Apr 2017

\begin{abstract}
Objective: Hepatic fibrosis is a wound-healing process in the liver with chronic injury and is characterized by an excess production and deposition of extracellular matrix (ECM) components. Our aim is to investigate the hepatoprotective effects of caffeine against CCL4-induced liver fibrosis in rats and to be compared with the reference standard $\mathrm{N}$-acetylcysteine (NAC).

Methods: Rats were divided into 5 groups $(n=8)$, the $1^{\text {st }}$ group served as normal control, the $2^{\text {nd }}$ group received corn oil, the $3^{\text {rd }}$ group is a fibrosis control and the remaining two groups received in addition to $\mathrm{CCL}_{4}, \mathrm{NAC}(150 \mathrm{mg} / \mathrm{kg} /$ day) as a reference treatment and caffeine (15 mg/kg/day). At the end of experimental period the following parameters were measured, specific fibrosis biomarkers [hepatic transforming growth factor $\beta 1$ (TGF$\beta 1$ ) and hepatic hydroxyproline (HYP)], liver function biomarkers [serum alanine transaminase (ALT), aspartate transaminase (AST), total bilirubin and albumin], lipid profile [serum triglycerides, total cholesterol, low density lipoprotein cholesterol (LDL-Ch) and high density lipoprotein cholesterol (HDL-Ch)], inflammatory biomarkers [serum tumor necrosis factor alpha (TNF- $\alpha$ ), hepatic myeloperoxidase (MPO)], oxidative stress biomarkers [hepatic malondialdehyde (MDA), glutathione (GSH) and catalase (CAT)], relative liver body weight and liver histopathological study.
\end{abstract}

Results: Caffeine significantly improved all the aforementioned biochemical parameters and liver sections obtained from this group showed prominent histopathological improvement.

Conclusion: Caffeine hepatoprotective effects may be due to modulation of the fibrous scar formation, Improvement of liver function, Antiinflammatory and antioxidant potentials.

Keywords: Liver fibrosis, Rat, $\mathrm{CCL}_{4}, \mathrm{NAC}$, Caffeine

(C) 2017 The Authors. Published by Innovare Academic Sciences Pvt Ltd. This is an open access article under the CC BY license (http://creativecommons.org/licenses/by/4.0/) DOI: http://dx.doi.org/10.22159/ijpps.2017v9i6.17143

\section{INTRODUCTION}

Liver fibrosis results from chronic damage to the liver in conjunction with the accumulation of extracellular matrix (ECM) proteins, which is a characteristic of most types of chronic liver diseases [1]. Hepatic stellate cell (HSC) is the key fibrogenic element in response to chronic liver injury through activation into myofibroblasts which mainly secrete ECM. Bone-marrow-derived cells and circulating fibrocytes also have an important role in the hepatic fibrogenesis through the production of ECM [2]. The damaged hepatocytes, their membrane components, metabolites of toxic agents, and infiltrating inflammatory cells are the activators of Kupffer cells. The activated Kupffer cells release a number of soluble agents, including cytokines, such as transforming growth factor- $\beta$ (TGF- $\beta$ ), platelet-derived growth factor (PDGF), and tumor necrosis factor- $\alpha$ (TNF- $\alpha$ ), reactive oxygen species (ROS), and other factors causing inflammation and damage to hepatocytes [3].

As there is no specific treatment for liver fibrosis, so new classes of drugs are claimed to prevent and attenuate the progression of hepatic fibrosis. Caffeine is a purine alkaloid present in many popular beverages, including cocoa, tea and coffee. It is widely used medically as CNS, respiratory and cardiac stimulant, smooth muscle relaxant, analgesic and diuretic [4]. Caffeine containing beverages are known to have beneficial effects against liver diseases [5].

We noticed that most previous trials focused mainly on the ability of caffeine for diminishing inflammatory cell infiltrate, downregulation of pro-inflammatory cytokines, and up-regulation of antioxidant enzymes. However, our study tried in addition to turn lights on the protective effects of caffeine against the experimentally induced liver fibrosis in adult male rats as compared to the standard drug NAC. In addition, this study extends to give an idea about its mechanisms of hepatoprotection.

\section{MATERIALS AND METHODS}

Material

Animals

The investigation was performed on adult male Wistar rats, obtained from El-Nasr Company, Abo-Zabaal, Egypt, weighing 220$250 \mathrm{~g}$. Rats were kept in an air-conditioned $\left(25 \pm 1{ }^{\circ} \mathrm{C}\right)$, pathogencontrolled animal room in the animal facility of Faculty of Pharmacy, Nahda University, Egypt, for two weeks for adaptation before being subjected to laboratory experiments with free access to standard forage and tap water ad libitum. All experimental procedures of animal handling and drug administration were done according to the guidelines of the Nahda University Animal House, which followed the recommendations of the National Institutes of Health (NIH) Guide for Care and Use of Laboratory Animals (Publication No. 85-23, revised 1985).

\section{Drugs, chemicals and reagent kits}

$\mathrm{CCl}_{4}$ was purchased from El-Nasr Chemical Company (Abou-Zaabal, Cairo, Egypt). Corn oil was purchased from Sigma-Aldrich Chemical Company (St. Louis, MO, USA). NAC and caffeine were purchased from Euromedex Company (France). Tissue colorimetric assay kits of HYP, tissue enzyme-linked immune-Sorbent assay (ELISA) kits of TGF- $\beta 1$ and tissue colorimetric kits of MPO and MDA were purchased from the CliniLab Company (Cairo, Egypt). Serum enzyme immunoassay technique (ELISA) TNF- $\alpha$ kit was obtained from the Glory Science Company (St. Del Rio, USA). Tissue colorimetric GSH, CAT kits and Serum colorimetric kits of ALT, AST, albumin, bilirubin, HDL, total cholesterol and TGs was purchased from the Bio Diagnostic Company (Giza, Egypt). All other chemicals, solvents and reagents used were of the highest analytical grade commercially available. 


\section{Experimental design}

Rats were randomly allocated into 5 weight-matched groups, each of 8 rats. The first group was kept as a normal control group and received only saline $5 \mathrm{ml} / \mathrm{kg} /$ orally/day. The second group was considered as a corn oil group and received only corn oil $1 \mathrm{ml} / \mathrm{kg} / \mathrm{i}$. p two times per week. The remaining three groups received intra-peritoneal $\mathrm{CCL}_{4}$ in corn oil (1:1) at a dose of $2 \mathrm{ml} / \mathrm{kg}$ body weight twice per week for $5 \mathrm{w}$ [6]; one of them was left as a fibrosis control group. The other remaining groups received the following treatments; NAC $150 \mathrm{mg} / \mathrm{kg} /$ day [7] as a reference treatment and caffeine $15 \mathrm{mg} / \mathrm{kg} /$ day [8]. All the aforementioned doses of the drug treatments were determined with pilot trials guided by the published literatures and were applied orally daily for 5 consecutive weeks, starting from the first day of induction. Blood and liver tissue samples were withdrawn $24 \mathrm{~h}$ after the last dose.

\section{Methods}

\section{Induction of liver fibrosis}

Induction of liver fibrosis was performed by intra-peritoneal injection of ats with $\mathrm{CCL}_{4}$ (1:1 in corn oil) at a dose of $2 \mathrm{ml} / \mathrm{kg}$ body weight twice per week for 5 consecutive weeks [6].

\section{Serum samples}

Twenty four hours, after the last dose, animals were lightly anesthetized. Blood samples were collected from the retro-orbital plexus in centrifuge tubes. After coagulation at room temperature, blood samples were centrifuged at 3000 RPM for 10 min using a cooling centrifuge (Sigma 3$30 \mathrm{k}$, USA), with the clear serum layer withdrawn and stored at $-80^{\circ} \mathrm{C}$ in a deep freezer (Als Angelantoni Life Science, Italy) for the assay of ALT, AST, albumin, bilirubin, triglycerides, cholesterol, HDL and TNF- $\alpha$.

\section{Assessment of serum biomarkers}

Serum TNF- $\alpha$ was assessed by quantitative sandwich enzyme immunoassay technique previously described[9]. Serum ALT and AST were assessed according to the method described previously by colorimetric assay [10]. Serum HDL was assessed by colorimetric assay and total cholesterol (TC) was assessed by an enzymatic colorimetric method based on the principle previously described [11], while LDL was assessed according to Formula: LDL = TC-HDL-TG/5.0 (mg/dL) [12]. Serum TGs was assessed by an enzymatic colorimetric method as previously described [13], while serum bilirubin [14] and serum albumin [15] were assessed calorimetrically as previously described.

\section{Calculation of relative body weight}

After the animals have been weighed, euthanized livers were dissected out and washed several times with $0.9 \%$ sterile saline solution to remove any blood from the tissues and then the livers were pressed between filter paper to absorb the excess saline solution. Each liver was weighed and the relative liver body weights were calculated from the following equation:

$$
\text { Relative liver body weight }=\frac{\text { weight of liver }(\mathrm{gm}) X 100}{\text { Body weight of rat }(\mathrm{gm})}
$$

\section{Preparation of liver homogenate}

Livers were cut into small pieces, and then homogenized in ice-cold 0.1 $\mathrm{M}$ phosphate buffer saline (PBS) at $\mathrm{pH} 7.4$ using tissue homogenizer. Aliquots of liver homogenates (10\%) were centrifuged at 4000 RPM for $15 \mathrm{~min}$ at $4^{\circ} \mathrm{C}$ and the supernatant was collected.

\section{Assessment of liver homogenate biomarkers}

Hepatic TGF- $\beta 1$ was assessed by Rat TGF- $\beta 1$ ELISA kit based on the principle previously described [16], while hepatic HYP was assessed by colorimetric assay based on the principle previously described [17]. Hepatic glutathione [18], catalase [19], MDA [20] and MPO [21] activity were assessed by colorimetric assay.

\section{Histopathological study}

Soon after blood withdrawal, rats were rapidly killed by cervical dislocation and parts of liver tissues were carefully separated and preserved in $10 \%$ formalin solution in saline and kept till becoming hard enough to be sectioned. Sections $5 \mu \mathrm{m}$ thick were prepared and stained with routine Hematoxylin and Eosin ( $\mathrm{H}$ and E) [22], and were investigated by the aid of two experienced pathologists blinded to the experiment.

\section{Statistical analysis}

Data were expressed as means of 8 values \pm standard error of the mean (SEM). All statistical analysis was performed using one way analysis of variance (ANOVA) test followed by Tukey-Kramer multiple comparisons test using statistical package for social sciences (SPSS; version 19.0) computer software program (SPSS Inc., Chicago, IL, USA), with the value of $\mathrm{p}<0.05$ considered statistically significant.

\section{RESULTS}

Biochemical estimations

\section{Effect of NAC or caffeine on specific fibrosis markers}

$\mathrm{CCL}_{4}$ significantly increased the hepatic content of TGF- $\beta_{1}$ and HYP as compared to normal control and corn oil groups. NAC or caffeine significantly decreased the hepatic content of TGF- $\beta_{1}$ (fig. 1) and HYP (fig. 2) as compared with fibrosis control group.

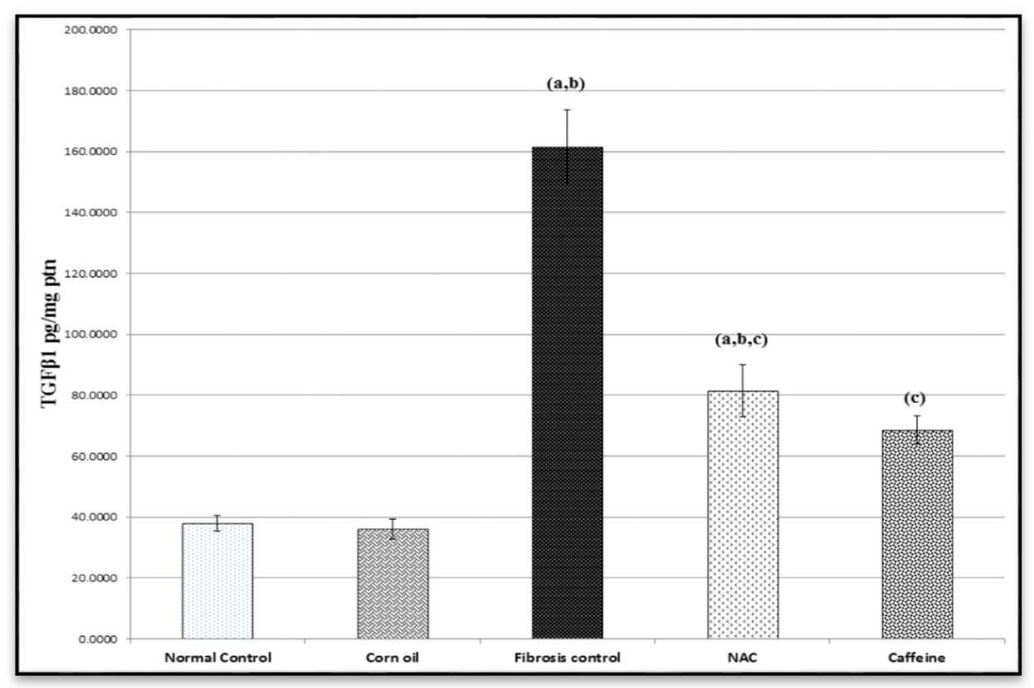

Fig. 1: Effect of NAC or caffeine on hepatic content of TGF- $\beta 1$ in rats with experimentally-induced liver fibrosis Each bar represents the mean of 8 animals \pm standard error of the mean (SEM), aSignificantly different from normal control group value at p<0.05, bSignificantly different from corn oil control group value at $\mathbf{p}<0.05$, cSignificantly different from fibrosis control group value at $p<0.05$, dSignificantly different from NAC treatment group value at $p<0.05$ 


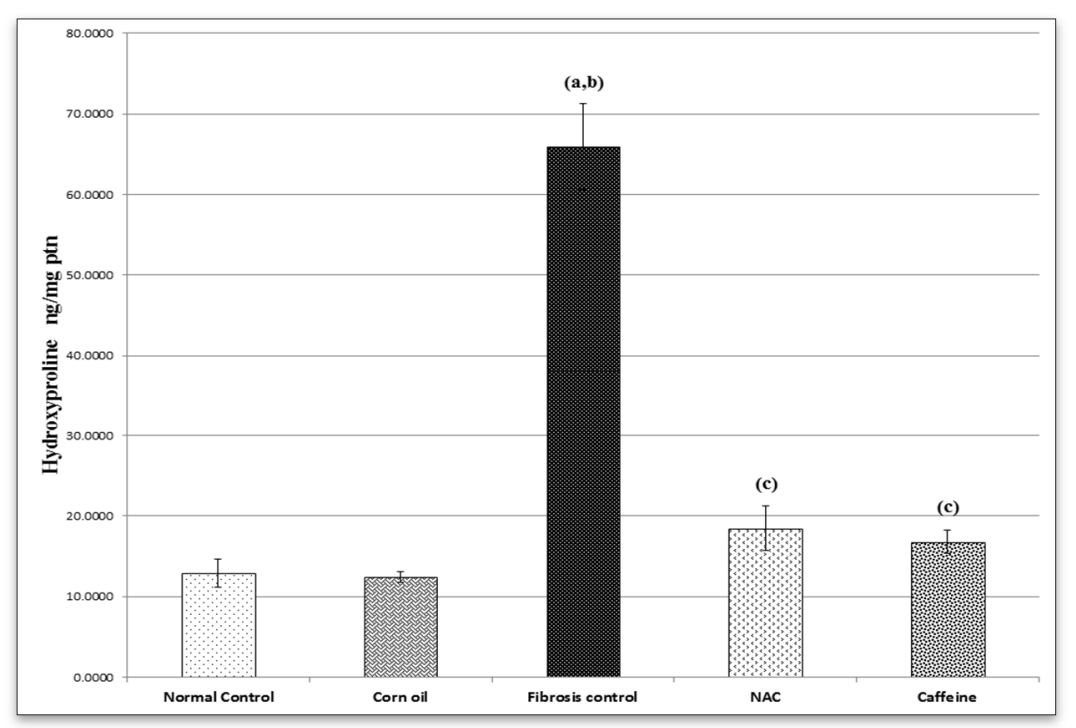

Fig. 2: Effect of NAC or caffeine on hepatic content of hydroxyproline in rats with experimentally-induced liver fibrosis, Each bar represents the mean of 8 animals \pm standard error of the mean (SEM), aSignificantly different from normal control group value at $p<0.05$, bSignificantly different from corn oil control group value at $\mathbf{p}<0.05$, 'Significantly different from fibrosis control group value at $p<0.05$, dSignificantly different from NAC treatment group value at $p<0.05$

Effect of NAC or caffeine on cytokine, inflammatory markers and the relative liver body weights

Fibrosis control group showed a significant increase in the serum level of TNF- $\alpha$ and the hepatic content of MPO as compared to the normal control and corn oil groups. Regarding the groups treated with NAC or caffeine they significantly improved the serum level of TNF- $\alpha$ and the hepatic content of MPO (table 1).

In addition, the fibrosis control group showed a significant increase in the relative liver body weight as compared to the normal control and corn oil groups. Treatment of rats with NAC or caffeine significantly improved the relative liver body weight as compared to the fibrosis control rats (table 1).

\section{Effect of NAC or caffeine on the liver function markers}

$\mathrm{CCl}_{4}$-treated group showed a significant increase in the serum level of ALT, AST and total bilirubin, while the serum level of albumin was significantly reduced as compared to the normal control and corn oil groups. Treatment of rats with NAC or caffeine significantly improved serum levels of ALT, AST, albumin and total bilirubin as compared to $\mathrm{CCl}_{4}$-treated group. Caffeine showed significantly better improvement of AST as compared to the standard NAC (table 2).

Table 1: Effect of NAC or caffeine on serum TNF- $\alpha$, hepatic MPO and the relative liver body weights in rats with experimentally-induced liver fibrosis

\begin{tabular}{lll}
\hline $\begin{array}{l}\text { Parameters } \Rightarrow \\
\text { Groups } \mathbb{N}\end{array}$ & $\begin{array}{l}\text { TNF- } \boldsymbol{\alpha} \\
\text { (pg/ml) }\end{array}$ & $\begin{array}{l}\text { MPO } \\
\text { (u/mg ptn) }\end{array}$ \\
\hline Normal control (5 ml saline/kg/p. o.) & $31.55 \pm 1.84$ & $2.97 \pm 0.25$ \\
Corn oil (1 ml/kg/i. p.) & $31.03 \pm 1.14$ & $2.75 \pm 0.15$ \\
Fibrosis control CCL4 with corn oil (1:1) (2 ml/kg/i. p.) & $131.85 \pm 5.63^{\mathrm{ab}}$ & $16.76 \pm 1.42^{\mathrm{ab}}$ \\
NAC (150 mg/kg, p. o.) & $83.16 \pm 4.42^{\mathrm{abc}}$ & $6.40 \pm 1.11^{\mathrm{bc}}$ \\
Caffeine (15 mg/kg, p. o.) & $62.2 \pm 7.32^{\mathrm{abc}}$ & $5.60 \pm 0.51^{\mathrm{c}}$ \\
\hline
\end{tabular}

Each value represents the mean of 6-8 animals \pm standard error of the mean (SEM). Statistical analysis was determined using one-way ANOVA test followed by Tukey-Kramer multiple comparisons test. Differences between group means were considered significant at p<0.05, aSignificantly different from normal control group value at $\mathrm{p}<0.05$, bignificantly different from corn oil control group value at $\mathrm{p}<0.05$, $\mathrm{Significantly} \mathrm{different} \mathrm{from}$ fibrosis control group value at $\mathrm{p}<0.05$, dSignificantly different from NAC treatment group value at $\mathrm{p}<0.05$.

Table 2: Effect of NAC or caffeine on serum levels of ALT, AST, albumin and total bilirubin in rats with experimentally-induced liver fibrosis

\begin{tabular}{lllll}
\hline $\begin{array}{l}\text { Parameters } \Rightarrow \\
\text { Groups } \mathbb{l}\end{array}$ & ALT(u/l) & AST(u/l) & Albumin (gm/dl) & Bilirubin (mg/dl) \\
\hline Normal control (5 ml saline/kg/p. o.) & & & & \\
Corn oil (1 ml/kg/i. p.) & $18 \pm 1.29$ & $13.5 \pm 1.08$ & $4.75 \pm 0.40$ & $1.03 \pm 0.07$ \\
Fibrosis control CCL4 with corn oil (1:1) (2 ml/kg/i. p.) & $15.16 \pm 1.97$ & $15.16 \pm 0.87$ & $5.05 \pm 0.28$ & $0.93 \pm 0.04$ \\
NAC (150 mg/kg, p. o.) & $39.16 \pm 7.36^{\mathrm{ab}}$ & $54.66 \pm 2.81^{\mathrm{ab}}$ & $1.42 \pm 0.13^{\mathrm{ab}}$ & $1.83 \pm 0.20^{\mathrm{ab}}$ \\
Caffeine (15 mg/kg, p. o.) & $49.5 \pm 5.04^{\mathrm{abc}}$ & $33.5 \pm 2.76_{\mathrm{abc}}$ & $3.05 \pm 0.13^{\mathrm{abc}}$ & $1.02 \pm 0.044^{\mathrm{c}}$ \\
\hline
\end{tabular}

Each value represents the mean of 6-8 animals \pm standard error of the mean (SEM). Statistical analysis was determined using one-way ANOVA test followed by Tukey-Kramer multiple comparisons test. Differences between group means were considered significant at $p<0.05$, aSignificantly

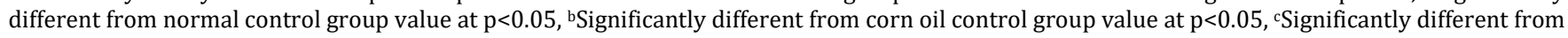
fibrosis control group value at $p<0.05$, dSignificantly different from NAC treatment group value at $p<0.05$ 


\section{Effect of NAC or caffeine on lipid profile markers}

Treatment of rats with $\mathrm{CCL}_{4}$ produced a significant increase in serum TGs, LDL and total cholesterol levels and a significant reduction in serum level of HDL as compared to normal control and corn oil groups. On the other hand, treatment of rats with NAC or caffeine significantly improved the previous parameters as compared to the fibrosis control group (table 3 ).

Table 3: Effect of NAC or caffeine on serum levels of triglycerides, total cholesterol, HDL and LDL in rats with experimentally-induced liver fibrosis

\begin{tabular}{|c|c|c|c|c|}
\hline $\begin{array}{l}\text { Parameters } \Rightarrow \\
\text { Groups } \mathbb{l}\end{array}$ & $\begin{array}{l}\text { Triglycerides } \\
\text { (mg/dl) }\end{array}$ & $\begin{array}{l}\text { Cholesterol } \\
(\mathrm{mg} / \mathrm{dl})\end{array}$ & HDL (mg/dl) & LDL (mg/dl) \\
\hline Normal control (5 ml saline/kg/p. o.) & $90.56 \pm 6.03$ & $146.2 \pm 5.82$ & $61.2 \pm 1.01$ & $66.97 \pm 5.75$ \\
\hline Corn oil ( $1 \mathrm{ml} / \mathrm{kg} / \mathrm{i} . \mathrm{p})$. & $82.03 \pm 3.39$ & $144.73 \pm 6.31$ & $63.2 \pm 1.47$ & $65.12 \pm 6.32$ \\
\hline Fibrosis control CCL 4 with corn oil (1:1) ( $2 \mathrm{ml} / \mathrm{kg} / \mathrm{i}$. p.) & $133.58 \pm 3.38 \mathrm{ab}$ & $237.96 \pm 13.31^{\mathrm{ab}}$ & $26.8 \pm 1.69 \mathrm{ab}$ & $184.45 \pm 14.09 \mathrm{ab}$ \\
\hline NAC (150 mg/kg, p. o.) & $98.61 \pm 3.84^{c}$ & $188.7 \pm 5.01^{\mathrm{abc}}$ & $37.83 \pm 2.51^{\mathrm{abc}}$ & $146.14 \pm 13.23^{\mathrm{abc}}$ \\
\hline Caffeine (15 mg/kg, p. o.) & $94.7 \pm 4.52^{c}$ & $163.56 \pm 3.95 \mathrm{c}$ & $50.4 \pm 1.47$ abcd & $94.22 \pm 4.49 \mathrm{~cd}$ \\
\hline
\end{tabular}

Each value represents the mean of 6-8 animals \pm standard error of the mean (SEM). Statistical analysis was determined using one-way ANOVA test followed by Tukey-Kramer multiple comparisons test. Differences between group means were considered significant at p<0.05, aSignificantly different from normal control group value at $\mathrm{p}<0.05$, bSignificantly different from corn oil control group value at $\mathrm{p}<0.05$, $\mathrm{Significantly} \mathrm{different} \mathrm{from}$ fibrosis control group value at $\mathrm{p}<0.05$, dSignificantly different from NAC treatment group value at $\mathrm{p}<0.05$

\section{Effect of NAC or caffeine on oxidative stress markers}

Fibrosis control rats showed a significant increase in hepatic MDA content coupled with a significant decrease in hepatic GSH content and
CAT activity as compared to normal control and corn oil rats. Treatment of rats with NAC or caffeine significantly improved the hepatic content of MDA, GSH and CAT. Caffeine showed significantly better improvements of MDA as compared to the standard NAC (table 4).

Table 4: Effect of NAC or caffeine on hepatic content of MDA, catalase and GSH in rats with experimentally-induced liver fibrosis

\begin{tabular}{llc}
\hline $\begin{array}{l}\text { Parameters } \Rightarrow \\
\text { Groups } \sqrt{ }\end{array}$ & MDA (nmol/mg ptn) & Catalase (mmol/mg) \\
\hline Normal control(5 ml saline/kg/p. o) & $1.19 \pm 0.07$ & $117.35 \pm 2.38$ \\
Corn oil (1 ml/kg/i. p.) & $1.38 \pm 0.14$ & $118.95 \pm 3.88$ \\
Fibrosis control CCL with corn oil (1:1)(2 ml/kg/i. p.) & $21 \pm 1.87$ ab & $45.96 \pm 3.60^{\mathrm{ab}}$ \\
NAC (150 mg/kg, p. o.) & $14.53 \pm 1.51^{\mathrm{abc}}$ & $92.56 \pm 6.344^{\mathrm{abc}}$ \\
Caffeine (15 mg/kg, p. o.) & $5.3 \pm 1.2^{\mathrm{cd}}$ & $18.91 \pm 3.33$ \\
\hline
\end{tabular}

Each value represents the mean of 6-8 animals \pm standard error of the mean (SEM). Statistical analysis was determined using one-way ANOVA test followed by Tukey-Kramer multiple comparisons test. Differences between group means were considered significant at p<0.05, aSignificantly different from normal control group value at $p<0.05$, bSignificantly different from corn oil control group value at $p<0.05$, cSignificantly different from fibrosis control group value at $\mathrm{p}<0.05$, dSignificantly different from NAC treatment group value at $\mathrm{p}<0.05$.

\section{Histopathological study}

Normal control and corn oil rat liver sections showed a normal hepatic architecture with central vein and radiating cords of normal hepatocytes with central rounded vesicular nuclei and prominent nucleoli. Hepatic cords are separated by blood sinusoids lined with endothelium and Von-Kupffer cells (fig. 3: A and B). Fibrosis control rat liver sections showed dilated congested blood vessels with dilated congested blood sinusoids and activated Von Kupffer cells. Some Hepatocytes show cytoplasmic lipid vacuolations with increased fibrous tissue (fig. 3: C). However, sections obtained from rats treated with NAC showed normal central vein and blood sinusoids, in addition to normal acidophilic hepatocytes with vesicular nuclei and activated von kupffer cells can be noticed (fig. 3: D). Caffeine treated fibrotic rat liver sections also showed prominent histopathological improvement with slightly dilated congested central vein and blood sinusoids.

Most hepatocytes are normal with acidophilic cytoplasm and vesicular nuclei and activation of Von Kupffer cells can be also observed (fig. 3: E).

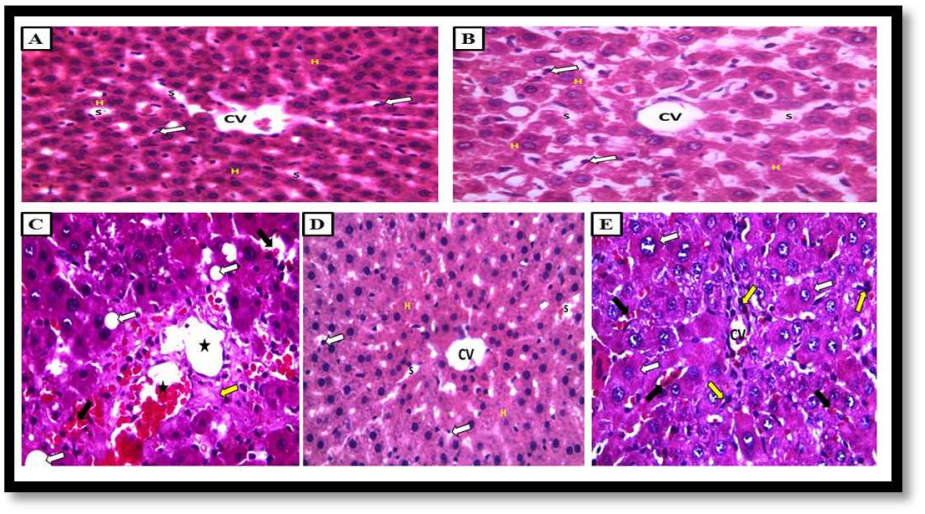

Fig. 3: Photomicrograph of liver obtained from, A: Normal Control Group (CV: Central Vein, H: Hepatocytes, S: Sinusoids, White Arrow: Von-Kupffer Cells), B: Corn Oil Group (CV: Central Vein, H: Hepatocytes, S: Sinusoids, White Arrow: Von-Kupffer Cells), C: Fibrosis Control Group(CCL4 in corn oil) (Astrix: Dilated Congested Blood Vessels, Black Arrow: Dilated Congested Blood Sinusoids and Activated VonKupffer Cells, White Arrow: Lipid Vacuolations, Yellow Arrow: Fibrous Tissue), D: NAC Group (CV: Central Vein, H: Hepatocytes, S: Sinusoids, White Arrow: Von-Kupffer, Cells), E: Caffeine Group (CV: Central Vein, Black Arrow: Blood Sinusoids, White Arrow: Hepatocytes with acidophilic cytoplasm and vesicular nuclei, Yellow Arrow: Activated Von-Kupffer Cells 


\section{DISCUSSION}

In the present study, we have evaluated the possible hepatoprotetcive effects of caffeine against $\mathrm{CCL}_{4}$-induced liver fibrosis in adult male albino rats, in comparison with the standard agent NAC.

We chose caffeine in our study because the recent data and reviews demonstrated an inverse relationship between coffee and potentially other caffeinated beverage consumption and liver fibrosis [5].

According to the main findings of the present study, caffeine significantly improved the hepatic content of TGF- $\beta 1$, which reflects its antifibrotic action. This comes into agreement with the results of previous investigators who reported the heptoprotective effect of coffee and caffeine against liver injury induced by thioacetamide in male Wistar rats [23]. In addition, the antifibrotic action of caffeine was evaluated in our study by reducing the hepatic content of hydroxyproline which is an indicator for the deposition of collagen and this result are in harmony with that of previous investigators who reported an experimental evidence for the protective effects of coffee against liver fibrosis in sprague dawley (SD) male rats [24].

According to the findings of this study, the anti-inflammatory effect of caffeine was evidenced by suppression of TNF- $\alpha$ production, which comes into agreement with the results of previous investigators who reported the anti-inflammatory and antifibrotic effect of caffeine on experimentally induced liver fibrosis in Wistar rats by ntraperitoneal thioacetamide or bile duct ligation [8]. Besides that, the results of our study revealed the suppressive effect of caffeine on the hepatic content of MPO, which comes into agreement with results of previous work [25]. MPO is an early biomarker of inflammation, which plays an important role in the initiation and progression of acute and chronic inflammatory diseases [26].

Results of the current study revealed that caffeine improved hepatic cell function and integrity which evidenced by improved serum levels of the liver function biomarkers which disturbed during the progression of liver fibrosis and that comes in agreement with the results of previous work [4]. In addition, the results of this study showed significant improvement of the lipid profile which also disturbed during liver injury and fibrosis. The hypolipidemic effect of caffeine beverages in fatty liver injured rats was reported in previous work [27].

During liver injury and progression of fibrosis, damaged hepatocytes can release high amounts of reactive oxygen species (ROS), an excessive amount of ROS is highly toxic to cells and play a critical role in the initiation of fibrosis. Oxidative stress affects the major cellular components, including proteins, lipids and DNA [28]. The antioxidant activity of caffeine was evaluated in this study, which reflects its role against liver fibrosis through its ability to scavenge (ROS) and inhibition of oxidative stress. This result is in full agreement with that of previous investigators who reported the effect of caffeine on oxidative stress in liver and heart tissues of rats [29].

The results from this study showed that caffeine reduced the amount of fibrous tissue in the liver as it reduced the relative liver body weight as compared to the fibrosis group. The previous biochemical results are coupled with histopathological improvements observed in the caffeine group, which leads to a further confirmation of its hepatoprotective potential.

Other molecular mechanisms involved in experimental hepatic fibrosis prevention by caffeine, including inhibition of Snail- 1 and activation of Nrf2 that could be involved in this beneficial effect down-regulating profibrogenic genes and up-regulating antioxidant molecules [8].

Another important mechanism of the antifibrotic action of caffeine is based on that caffeine is a non-selective adenosine receptor antagonist, which binds with very similar (relatively high) affinity to both adenosine $\mathrm{A} 1$ and $\mathrm{A} 2 \mathrm{~A}$ receptors and adenosine is known to aggravate liver fibrosis via the adenosine A2A receptor (A2AR) which induces hepatic stellate cell (HSC) activation during liver fibrosis [30].

\section{CONCLUSION}

The current results clearly indicate the beneficial effects of caffeine in protection against liver fibrosis. Depending on the findings of the present study, it could be suggested that caffeine may exert its antifibrotic action through its inhibition of Snail-1, adenosine on A2A receptors and activation of $\mathrm{Nrf} 2$, antioxidant and anti-inflammatory potentials with the inhibition of the process of ECM deposition.

\section{CONTRIBUTION OF EACH AUTHOR}

Ali Ahmed Abo-Saif: help in the design of the model and selection of drugs.

Amira Morad Abo-Youssef: help in choosing biochemical parameters.

Marwa Mahmoud Khalaf: help in writing and revision of the paper.

Mostafa Kamal Mohammed: Application of the model, interpretation of results and writing the paper.

\section{CONFLICT OF INTERESTS}

Declared none

\section{REFERENCES}

1. Bataller R, Brenner DA. Liver fibrosis. J Clin Invest 2005;115:209-18.

2. Friedman SL. Evolving challenges in hepatic fibrosis. Nat Rev Gastroenterol Hepatol 2010;7:425-36.

3. Wu J, Zern MA. Hepatic stellate cells: a target for the treatment of liver fibrosis. J Gastroenterol 2000;35:665-72.

4. Rezaie A, Pashmforosh M, Karamallah M, Fazlara A, Haghighat N, Shahriari A. Hepatoprotective effects of caffeine on diethylnitrosamine induced liver injury in rtas. Bulg J Vet Med 2014;17:183-90.

5. Dranoff JA, Feld JJ, Lavoie EG, Fausther M. How does coffee prevent liver fibrosis? Biological plausibility for recent epidemiological observations. Hepatology 2014;60:464-7.

6. Ay H, Wk L, Hl C, Fk C, My G, Kk C, et al. Effect of celecoxib on experimental liver fibrosis in rat. Liver Int 2006;26:125-36.

7. Kamalakkannan N, Rukkumani R, Aruna K, Varma PS, Viswanathan P, Menon VP. Protective effect of N-Acetyl cysteine in carbon tetrachloride-induced hepatotoxicity in rats. Iran J Pharmacol Ther 2005;4:118-23.

8. Gordillo-Bastidas D, Oceguera-Contreras E, Salazar-Montes A, González-Cuevas J, Hernández-Ortega LD, Armendáriz-Borunda J. Nrf2 and snail-1 in the prevention of experimental liver fibrosis by caffeine. World J Gastroenterol 2013;19:9020-33.

9. Brouckaert P, Libert C, Everaerdt B, Takahashi N, Cauwels A, Fiers W. Tumor necrosis factor, its receptors and the connection with interleukin 1 and interleukin 6 . Immunobiology 1993;187:317-29.

10. Bergmeyer HU, Horder M, Rej R. IFCC method for alanine aminotransferase and aspartate aminotransferase. J Clin Chem Clin Biochem 1976;24:481-510.

11. Watson D. A simple method for the determination of serum cholesterol. Clin Chim Acta 1960;5:637-43.

12. Friedewald WT, Levy RI, Fredrickson DS. Estimationof the concentration of low-density lipoprotein cholesterol in plasma, without use of the preparative ultracentrifuge. Clin Chem 1972;18:499-502.

13. Fossati $P$, Principe L. Serum triglycerides determined calorimetrically with an enzyme that produces hydrogen peroxide. Clin Chem 1982;28:2077-80.

14. Malloy HT, Evelyn KA. The determination of bilirubin with the photometric colorimeter. J Biol Chem 1937;119:481-90.

15. Doumas BT, Biggs HG. Standard methods of clinical chemistry. Academic Press NY; 1976. p. 7.

16. Blanchette F, Day R, Dong W, Laprise M, Dubois CM. TGF beta1 regulates gene expression of its own converting enzyme furin. Am Soc Clin Investig 1997;99:1974-83.

17. Patiyal SN, Katoch SS, Hill S. Tissue specific and variable collagen proliferation in swiss albino mice treated with clenbuterol. Physiol Res 2006;55:97-103.

18. Beutler E, Duron O, Kelly MB. Improved method for the determination of blood glutathione. J Lab Clin Med 1963;61:882-8.

19. Aebi H. Catalase in vitro. Methods Enzymol 1984;105:121-6.

20. Satoh K. Serum lipid peroxide in cerebrovascular disorders determined by a new colorimetric method. Clin Chim Acta 1978;90:37-43. 
21. Weiss SJ, Klein R, Slivka A, Wei M. Chlorination of taurine by human neutrophil. J Clin Invest 1982;70:598-607.

22. Branchroft GD, Steven A. Theory and practice of histological technique. London, 4 th ed. Churchil Livingstone Publications; 1983. p. 99-112.

23. Furtado KS, Prado MG, Aguiar E, Silva MA, Dias MC, Rivelli DP, et al. Coffee and caffeine protect against liver injury induced by thioacetamide in male wistar rats. Basic Clin Pharmacol Toxicol 2012;111:339-47.

24. Shin J, Wang J, Kang J. Experimental evidence for the protective effects of coffee against liver fibrosis in SD rats. Soc Chem Ind 2010;90:450-5.

25. Barcelos RP, Souza MA, Amaral GP, Stefanello ST, Bresciani G, Fighera MR, et al. Caffeine intake may modulate inflammation markers in trained rats. Nutrients 2014;6:1678-90.

26. Olza J, Aguilera CM, Gil-Campos M, Leis R, Bueno G, MartinezJimenez MD, et al. Myeloperoxidase Is an early biomarker risk in prepubertal obese children. Diabetes Care 2012;35:2373-6.
27. Abd El-ghany MA, Nagib RM, El-Saiyed HM. Hypolipidemic effect of caffeine beverages in fatty liver injured rats. J Appl Sci Res 2012;8:1502-9.

28. Cichoż-lach H, Michalak A. Oxidative stress as a crucial factor in liver diseases. World J Gastroenterol 2014;20:8082-91.

29. Pașaoğlu H, Ebru F, Demİr O, Demİrtaș CY, Hussein A. Th e effect of caffeine on oxidative stress in liver and heart tissues of rats. Turk J Med Sci 2011;41:665-71.

30. Wang $\mathrm{H}$, Guan W, Yang W, Wang Q, Zhao H, Yang F, et al. Caffeine inhibits the activation of hepatic stellate cells induced by acetaldehyde via adenosine A2A receptor mediated by the cAMP/PKA/SRC/ERK1/2/P38 MAPK signal pathway. PLOS One 2014;9:1-11.

\section{How to cite this article}

- Mostafa Kamal Mohamed, Marwa Mahmoud Khalaf, Amira Morad Abo-Youssef, Ali Ahmed Abo-Saif. Caffeineas a promising antifbrotic agent against $\mathrm{CCL}_{4}$-induced liver fibrosis. Int J Pharm Pharm Sci 2017;9(6):42-47. 